\title{
The perspective of capability providers in creating a sustainable I4.0 environment
}

\author{
Alessandra Lardo \\ Department of Business and Economics, Parthenope University of Naples, \\ Napoli, Italy \\ Daniela Mancini \\ Faculty of Law, University of Teramo, Teramo, Italy \\ Niccolò Paoloni \\ Department of Engineering, Roma Tre University, Rome, Italy, and \\ Giuseppe Russo \\ Department of Economics and Law, University of Cassino and Southern Lazio, \\ Cassino, Italy
}

\begin{abstract}
Purpose - With the increasing pressures towards global sustainability and the transition to Industry 4.0 (I4.0), the collaboration between firms and other key stakeholders is essential. Value is no longer created by firms acting autonomously, but rather by firms acting together with external parties. Therefore, the aim of this study is to explore the potential contribution of capability providers to a Sustainable I4.0 Environment as an additional perspective regarding the management decisions of a smart and sustainable business model (SSBM) transformation of big corporations.

Design/methodology/approach - An in-depth qualitative case study of Futuryng INC., which is a company based in Silicon Valley, New York and Italy, is presented and analysed through interviews, secondary sources and using a triangulation approach. The company is a Connected Technologies Ecosystem, which acts as a provider of technology building blocks (capability) able to design and release end-to-end Information Technologies-Internet of Things-Operational Technologies (IT-IoT-OT) Solutions.

Findings - From the case study, the authors determine that the success of big corporations' SSBM transformation requires a Sustainable I4.0 Environment approach where capability providers play a relevant role and act as enablers. Then, the authors develop a framework by adopting an actor perspective, called the Sustainable I4.0 Environment, highlighting the contribution of the capability provider in the sustainable I4.0 business model transformation of a big corporation.

Practical implications - The authors' analysis clarifies that the successful execution of a sustainable I4.0 business model transformation requires integrated thinking for management decisions and a co-creation approach with capability providers, along with an open innovation process.

Originality/value - In the analysis of I4.0 and sustainability issues, previous studies only focus on implementing firms and view the environment merely as a background in which act forces of sustainability and I4.0. A comprehensive overview of the Sustainable I4.0 Environment, which considers actors and their contribution, is lacking. By integrating the literature review with the case study, the authors' research proposes a comprehensive framework to guide the decision process of transformation from a traditional business model (TBM) to an SSBM and considers one of the key actors involved, the capability providers.
\end{abstract}

Keywords Industry 4.0, Sustainable business model, Capability providers, Sustainable industry 4.0 environment

Paper type Research paper

(C) Alessandra Lardo, Daniela Mancini, Niccolò Paoloni and Giuseppe Russo. Published by Emerald Publishing Limited. This article is published under the Creative Commons Attribution (CC BY 4.0) licence. Anyone may reproduce, distribute, translate and create derivative works of this article (for both commercial and non-commercial purposes), subject to full attribution to the original publication and authors. The full terms of this licence may be seen at http://creativecommons.org/licences/by/4.0/legalcode

Creating a sustainable I4.0

environment

Received 30 September 2019

Revised 24 February 2020

16 April 2020

Accepted 29 May 2020 
$\mathrm{MD}$

58,8

\section{Introduction}

The general economic crisis of the last decade has driven the rethinking of the traditional linear economic model and pushed the search for new sources of economic development. The early adopter countries - Germany, the United States, China, India and so on (Lin et al., 2017; Beier et al., 2017; Luthra et al., 2019) - and firms began to support the concept and implementation of sustainable development (SD) (Kiel et al., 2017; Lin et al., 2017) and circular economy (Nascimento et al., 2019) and to consider digital transformation and I4.0 (MartínezOlvera and Mora-Vargas, 2019) as key drivers of economic development.

Nowadays, most companies are moving towards an extensive application of I4.0 technologies, into their business processes, and are considering SD perspective in their business models (BMs). I4.0 consists of the application of some complementary technologies the so-called Cyber-Physical Systems (CPSs) - able to connect people, machine and objects into the companies' BM with the aim to better manage and control the value creation process (Birkel et al., 2019) and the supply chain (Rajput and Singh, 2019a). CPSs are "a new generation of systems with integrated computational and physical capabilities that can interact with humans through many new modalities" (Baheti and Gill, 2011).

According to the Triple Bottom Line (Elkington, 1997), SD includes three dimensions: economic (i.e. profitability and efficiency), environmental (i.e. resource consumption and emissions in the natural environment) and social (i.e. respect and inclusion for human and social capital) (Birkel et al., 2019).

The literature in this field is still in its infancy because, until recently, from both academia and practitioners, smart and sustainable issues have been considered as separate and independent concepts (Piccarozzi et al., 2018; Wu et al., 2018; Gazzola et al., 2019; Kamble et al., 2018; Schiavone et al., 2019). Conversely, a growing number of current studies are investigating the link between SD and smart technologies (Gazzola et al., 2019).

Some research works propose interpretative frameworks that link smart technologies, and in particular Industry 4.0, and sustainable issues (Wu et al., 2018; Stock and Seliger, 2016; Stock et al., 2018) while other researchers examine how companies can transform their BM in a smart and sustainable business model (SSBM) (Brenner, 2018; Kamble et al., 2018; Bressanelli et al., 2018).

The transformation of a company's BM into an SSBM is a very complex process due to the pervasiveness of the concepts involved. In fact, smart technologies are considered generative technologies and the way in which they affect organizations depends on the creative interpretation of possible implementation (McKinsey and Company, 2016; Agostini and Nosella, 2019). Among those technologies, CPSs are able to integrate physical and cyber capabilities as computing, communication, networking, self-organizing (Rajkumar et al., 2010; Rajput and Singh, 2019b). The current concept of sustainability has a wide meaning and involves several aspects of a firm's life, but it requires an integrated view at the company level if the aim is the spread of a new model for economic development. Therefore, currently, to sustain companies during BM innovation, we need more research in developing a holistic approach related to the three dimensions of Triple Bottom Line (Kiel et al., 2017; Lamboglia et al., 2017; De Sousa Jabbour et al., 2018; Braccini and Margherita, 2019); an integrated analysis regarding I4.0 technologies and a comprehensive vision in term of actors involved (Martínez-Olvera and Mora-Vargas, 2019). Particularly, cooperation between experts from operations, experts from IT, experts from business and managers is a key driver of BM transformation (McKinsey and Company, 2016; Martínez-Olvera and Mora-Vargas, 2019).

The aim of this research work is to explore the potential contribution of capability providers in the Sustainable I4.0 Environment as an additional perspective to that of the transforming firm, for the management of successful transformation towards an SSBM in big corporations. We propose a comprehensive and integrated framework to guide the decision process of the transformation from a TBM to an SSBM. In our proposition the Environment is both the external business background characterized by technological, social, political 
dynamics, within which is located the transforming firm (Brenner, 2018), and characterized by the key actors (capability providers, consulting firms) with which the transforming firm interacts to implement SSBM and the internal smart manufacturing context (Kamble et al., 2018) within which the firm activates the sustainable I4.0 transformation.

We adopt the perspective of capability providers. These are firms specialized in designing, developing, releasing, managing and evolving end-to-end Industrial Internet of Things (IIoT) solutions based on interoperable and pre-connected smart technologies, called capabilities as they have the ability to support specific processes (i.e. data streaming, predictive maintenance, industrial messaging, etc.).

Starting from the two main concepts of I4.0 and SD, and adopting a qualitative research method based on a single case study, we provide insight into the Sustainable I4.0 Environment.

Therefore, we can make explicit our research question as follows:

$R Q 1$. What could be the contribution of capability providers in configuring a Sustainable I4.0 Environment for the transition into SSBM of big companies?

The remaining work is organized as follows. In the second section, we develop a literature review highlighting features of IIoT and SD and the emerging gaps considering the link between these concepts. In the third section, we introduce the research methodology and the data collection phase. In the fourth section, we describe the main findings from the case study analysis by inserting interview extracts. Finally, we develop the discussion and conclusions, and we introduce implications for academics and practitioners and future research.

\section{Literature review}

To collect sources for an initial understanding of the relationship between I4.0 and SD, we consider the Scopus and Web of Science databases. Table 1 shows the details of the literature search we performed to collect a first group of useful articles. To enlarge the number of sources, in a second phase we also included some articles cited in the references of the first group.

Literature reviews (Piccarozzi et al., 2018; Kamble et al., 2018; Bonilla et al., 2018; MartinezOlvera and Mora-Vargas, 2019) in the fields of I4.0 and Sustainable BM have identified several topics and streams of research. Particularly, in regard to this research work, we focus on two main areas: the definition of I4.0 and its features and the analysis of an SBM in the digitalized era.

\subsection{Industry 4.0 and its features}

I4.0 is a new industrial model, which seems to have great potential in helping companies to face current challenges in the value creation process. It is an intelligent interconnection of machines, people, objects, information and communication systems along the value chain (Birkel et al., 2019). It is based on a cyber-physical infrastructure (Kiel et al., 2017), made by several technologies, which is the meeting point between physical processes, inside and

\begin{tabular}{ll} 
Items & Description \\
\hline Sources & Scopus \\
& Web of Science \\
Queries & Topic: "Smart technolog*" "Industry 4.0" and "sustainab*” "Sustain* business model*" \\
& Topic: "Industry 4.0" and "Internet of Things" and "sustainab*" \\
& Topic: "Industry 4.0" and "Cyber-physical systems" and "sustainab*" \\
& Topic: "Industry 4.0" and "flexible manufacturing" and "sustainab* \\
& Refined by: Languages, English; Subject Area, Business, Management and Accounting; Source \\
& Type, Articles
\end{tabular}

Creating a sustainable I4.0

environment

1761 
outside the company along the product life cycle, and their virtual projection, made by collecting a big amount of data (Stock and Seliger, 2016).

Integration in an I4.0 context assumes several nuances. Stock and Seliger (2016) distinguished horizontal and vertical integration, that is, the integration of the value creation processes cross-company along the product life cycle, considering not only the product value chain but also the other related value chains, and the interconnection and digitization of the value creation modules inside a company. According to Agostini and Nosella (2019), integration in I4.0 is due to the request of collaboration that necessarily comes out from the implementation of smart technologies. Collaboration regards suppliers and technology providers, outside the company, and functions and organizational units, inside it (McKinsey and Company, 2016). To effectively understand the implications of I4.0 model, some authors suggest the adoption of an integrated perspective that analyses the phenomenon from inside and outside company's boundaries (Agostini and Nosella, 2019).

Kamble et al. (2018) underline that interconnection regards, at a first and preliminary step, technologies, but it implies the integration of processes as an outcome of I4.0 technologies. Some studies analyse the concept of integration as the interaction and communication between human resources and machines and machine-machine integration (Kamble et al., 2018). In the first case, I4.0 must be implemented taking into account employees' values, knowledge and expertise to identify the most efficient and effective framework of integration between human and machines. While, in the second case, other studies analyse the most efficient way to combine different devices in order to collect relevant information from the physical system to the virtual one.

\subsection{Sustainability and its dimensions}

Currently, sustainability is one of the most frequent discourses informing practice and scientific debate. It is related to the concept of SD, introduced by the Bruntland Report, which is defined as "development that meets the needs of the present without compromising the ability of future generations to meet their own needs" (WCED, 1987). Recently, the concept has been adopted and reinforced by 2030 Development Agenda of the General Assembly of the United Nations, which based the 17 Sustainable Development Goals (SDG) on three main pillars: economic, social and environmental development. From the original concept, mainly applied to natural consumption, practitioners and academics share and debate sustainability as a multi-faced economic paradigm, which requires industrial organization to found value creation on the integration of economic development, balanced environment exploitation, social equality (Etzkowitz and Zhou, 2006; Stock et al., 2018). The economic dimension refers to the financial value creation that ensures the existence of a company and must be compatible with the other two dimensions. The environmental dimension refers to the preservation of the natural ecosystem when a company uses renewable resources and contains emission to a compatible level for environment preservation. The social dimension refers to the company's respect for human and social capital in managing the business (Muller and Voight, 2018; Braccini and Margherita, 2019; Birkel et al. 2019).

\subsection{The relationship between 14.0 and sustainable business models}

Currently, the scientific literature does not have a homogeneous understanding of the relationship between I4.0 and sustainability, maybe because I4.0 has initially been conceived as a technological phenomenon, born apart from sustainability matters, but essentially used to boost productivity, efficiency, the competitiveness of firms (Bonilla et al., 2018). I4.0 is sometimes seen as a paradigm that will help companies to move towards sustainable value creation (Stock and Seliger, 2016, p. 541) or as an enabler of the transition towards servitized business models (Bressanelli et al., 2018) or as an opportunity to implement SBMs 
(Martinez-Olvera and Mora-Vargas, 2019) and to reach sustainable aims integrating business partners in the value creation network (Stock and Seliger, 2016; Stock et al., 2018). Other researchers consider a bidirectional relationship as I4.0 creates opportunities and challenges for sustainability and circular economy in supply chain (Rajput and Singh, 2019), as well as sustainable practices create opportunities and challenges for I4.0 technologies implementation (Muller and Voigt, 2018; Cezarino et al., 2019). Conversely, other researchers highlight the risks of I4.0 in pursuing sustainable development (Birkel et al., 2019). Researchers underline the potential implication of wide adoption of I4.0, in the short and medium term, for energy and natural resources consumption and increase of pollution, for losses of several job roles (Braccini and Margherita, 2019) and for costs of implementation (Muller and Voigt, 2018).

Other studies (Trequattrini et al., 2016; Lin et al., 2017; Bonilla et al., 2018; Cezarino et al., 2019; Muller and Voigt, 2018) verify that positive or negative implications of I4.0 on sustainability depend on the phases (deployment, operation) and time (short, medium and long term) and on some macro (societal reaction, public policies, legal framework, homogeneous dissemination) and micro contingency aspects (company size, industry sector and role towards industry).

\subsection{I4.0 sustainable frameworks}

Moving from the relationship between I4.0 and sustainability, some authors try to formulate frameworks to interpret the transformation from a TBM towards a sustainable I4.0 business model (Stock and Seliger, 2016; Stock et al., 2018).

According to Kamble et al. (2018), sustainability is an outcome of the I4.0 ecosystem, as shown in Figure 1. They proposed a framework to represent the I4.0 sustainable environment that sequentially connects three main components: I4.0 technologies, which are combined in an efficient and effective way; process integration inside and outside the company along with its value chain networks; and sustainable outcomes, according to each dimension of the UN model as economic, automation and safety processes and environmental protection. Particularly, I4.0 technologies generate process integration and the resulting ecosystem generates sustainable outcomes (Kamble et al., 2018). The economic outcomes are cost saving in the process of development, the safety outcomes consist of better ways of working for

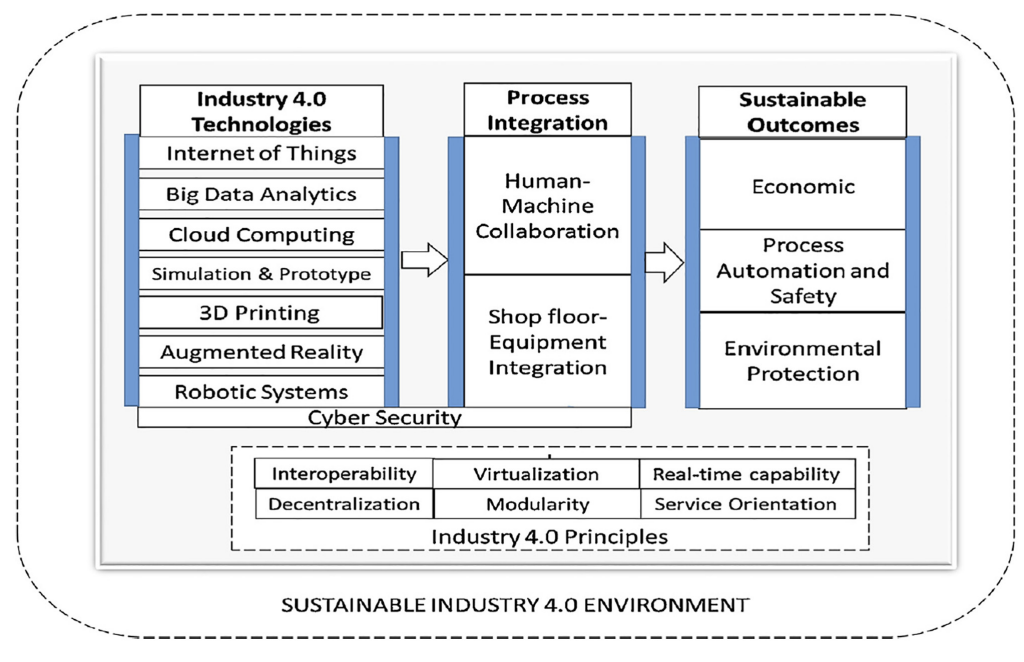

Creating a sustainable I4.0 environment

1763
Figure 1. Sustainable I4.0 environment from Kamble et al. (2018) 
$\mathrm{MD}$

58,8

1764

employees, and finally, environmental protection is the management and monitoring of resource consumption through data collected along with the value chain network.

Brenner (2018) proposed a model to interpret how a company can transform its BM into an SBM in a digitalized context, as shown in Figure 2. Its framework identifies three layers and related elements that occur in BM transformation: the external features of the environment, the organization capabilities and the individual culture of employees. These layers are linked from the bottom to the top and respective elements interrelate both horizontally and vertically.

\subsection{Literature review discussion}

From the previous analysis, studies seem to consider the relationship between I4.0 and sustainability in a deterministic way, and the point of view of the firm that has to implement I4.0 and to manage the transformation into an SSBM is the prevailing perspective of the analysis.

Even if the literature highlights that the success of the transition from a TBM into an SSBM depends on the integration of different perspectives and dimensions of the Environment, the existing frameworks suggest instead that a company can plan or monitor SSBM transformation without any consideration of the contribution of other actors involved in the transition.

Although publications in the field of I4.0 have been growing in the last five years, the I4.0 relationship with sustainability issues and SD has been poorly investigated (Kamble et al., 2018; Muller and Voigt, 2018; Wu et al., 2018). Currently, studies identify sustainable implications of I4.0 in an unstructured and generic way, from a theoretical point of view, and wondering about what are the companies' opportunities and challenges of I4.0 in pursuing sustainability in I4.0 projects. Less attention is focussed on considering contingency factors that can influence those relationships (Muller and Voigt, 2018); on adopting an integrated approach that considers simultaneously the three dimensions of sustainability (Triple Bottom Line) or the different technologies included in I4.0. Few studies develop empirical analysis, and most of them are case studies reporting firms' experiences or expert opinions in implementing I4.0 technologies, examining their implications (Kiel et al., 2017).

Scientific studies call for further investigations concerning the opportunities and challenges of I4.0 for firms that adopt or are going to adopt an SBM (Kamble et al., 2018; Kiel et al., 2017). Furthermore, additional research is required on how companies can transform their BM along the direction of sustainability in a digitalized context (Brenner, 2018). Even if some studies highlight that I4.0 has the potential to unlock sustainability

Figure 2.

Sustainable transformative business model from Brenner (2018)
- Transformative leadership

- Digital sustainable mindset
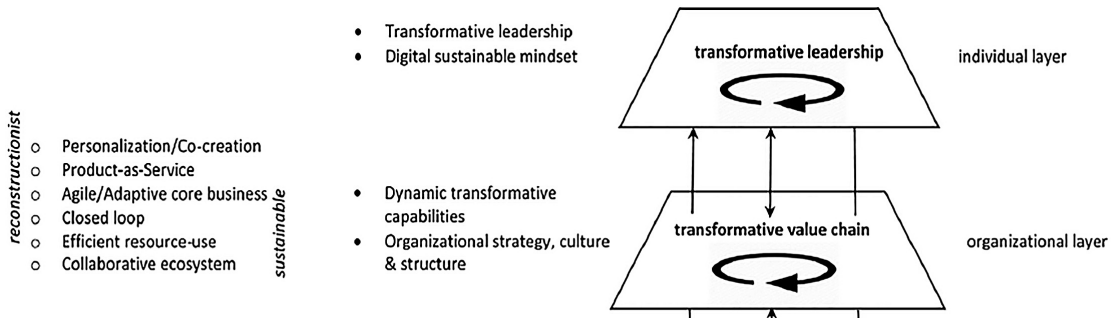

- (Digital) Technologies - Diminishing sector borders

Increased global competition

Changing Market needs

- Dissolving market and firm boundaries
- Dynamic transformative capabilities

- Organizational strategy, culture \& structure

- Technology

- Economy

- Society

- Environment

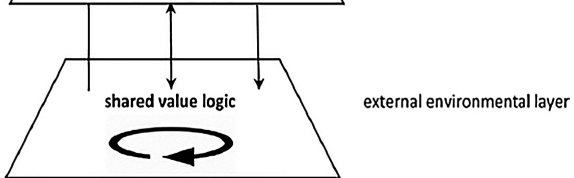


(Cezarino et al., 2019), it is mostly unknown how and to what extent (Bonilla et al., 2018) this could happen through smart technologies and how companies could obtain value from the combination of I4.0 and sustainability (De Man and Strandhagen, 2017; Martínez-Olvera and Mora-Vargas, 2019). The aim of this work is to answer that need for research.

Considering the limits of the extant literature, we decided to examine the relationship between the implementation of I4.0 technologies and sustainability issues by considering the perspective of capability providers. In fact, the implementation of I4.0 technologies does not automatically imply any sustainable effects, but requires the involvement of certain actors, such as the company itself, its consulting firms and its I4.0 capability providers, into the definition and the planning of successful I4.0 projects implementation in order to create a Sustainable I4.0 Environment.

\section{Research model and data collection}

For the purpose of this research, a qualitative study design was chosen since a comprehensive and systematic analysis of the Sustainable I4.0 Environment is still lacking, and this research design is particularly suitable in a new, complex and evolving context (Birkel et al., 2019). To support our analysis, a research protocol was implemented following the prescriptions stated in Yin (2014). This protocol was used to validate the results in terms of construction and internal and external validity. Table 2 presents the validation strategy.

First, we consider the construct validity by examining multiple data sources and construction through key components of the organization and then using two literature frameworks, selected because of their relevance on the issue of Industry 4.0 and SBMs (Kamble et al., 2018; Brenner, 2018).

Then, the first step in internal validation is ensuring that the selected case is an appropriate subject for study. This strategy considers the company's features and consistency with research aims, the willingness of the company to participate in the research and the preliminary analysis of information about the company. We choose the company Futuryng Inc., as an appropriate subject for this study because it presents distinctive features: it is a good example of an outstanding start-up company based in Silicon Valley, New York and Italy with more than 100 employees and collaborators only in its Italian ecosystem. Moreover, Futuryng is an ecosystem of connected technologies equipped with a basic technology architecture capable of delivering IIoT-I4.0 solutions by quickly integrating additional technologies. In fact, within the Futuryng ecosystem, several capabilities are incorporated and the most important areas are Data Composer, IoT Messaging, Artificial Intelligence, Metafyre, which is a hyper connectivity technology/capability that enables interoperability. Consistency with the research aims relies on the Futuryng competitive strategy of playing at an

\begin{tabular}{lll}
\hline Test & Strategy & Phase \\
\hline $\begin{array}{l}\text { Construct } \\
\text { validity }\end{array}$ & $\begin{array}{l}\text { Multiple data sources } \\
\text { Validation of the construction through the key components of the } \\
\text { organization } \\
\text { Integration of two frameworks developed by the literature } \\
\text { (Brenner, 2018; Kamble } \text { et al., 2018) }\end{array}$ & $\begin{array}{l}\text { Data collection } \\
\text { Design of the study }\end{array}$ \\
& $\begin{array}{l}\text { Construction of the } \\
\text { The company's features and consistency with research aims } \\
\text { validity }\end{array}$ & $\begin{array}{l}\text { Willingness of the company to participate in the research } \\
\text { Selection of the case }\end{array}$ \\
& $\begin{array}{l}\text { Preliminary analysis of multiple data sources and triangulation } \\
\text { for case acceptance }\end{array}$ & \\
External & Validation with external references & Construction of the \\
Validity & & findings
\end{tabular}

Creating a sustainable I4.0 environment

1765
Table 2.

Research validation strategy 
international level in the growing segment of the smart technology industry with active projects of I4.0 implementation in big corporations (i.e. Johnson and Johnson) operating in different sectors. Moreover, the top managers of Futuryng are aware of the lack of knowledge in the opportunities spread by the transformation of BMs towards I4.0 and sustainability, and therefore, they support the research team through a strong willingness to share their experiences, practices and perspective. The relevance of the case was finally confirmed by an analysis of information collected in a preliminary meeting with a top manager, through the company website, and institutional reports of IoT projects.

A common critique of the case study methodology involves problems with generalizing the findings. Yin (2014) countered that case studies are not designed to provide statistical generalizations. Rather, they seek to deliver analytical generalizability from the observations of a phenomenon with the aim of offering theoretical explanations that can be applied to identify similar cases. Given that one of our aims is to provide insights beyond mere empirical descriptions, we externally validated our conclusions with a triangulation process that was comprised of our data sources and external references.

The data were principally gathered between March 2019 and June 2019 (and subsequently until December 2019). The sequence and timeline of the data collection began with an initial interview of the Chief Operating Officer (COO) to capture his story in narrative form. After two more informal meetings, three semi-structured interviews with the Chief Executive Officer (CEO), the COO and the Chief IoT Solution Officer (CISO) were conducted to focus on specific aspects of the business activity following the track indicated in Table 3.

The interviews were conducted in Italian. The entire process was directed by a research team comprised of all four authors of this article to increase the validity and objectivity of the

\begin{tabular}{|c|c|c|}
\hline Interviewee & Content of the questions & $\begin{array}{l}\text { Primary source } \\
\text { code }\end{array}$ \\
\hline $\begin{array}{l}\text { Chief Executive } \\
\text { Officer } \\
\text { Co-Founder }\end{array}$ & $\begin{array}{l}\text { Futuryng approach to customers } \\
\text { Type and extensions of the I4,0 technologies provided } \\
\text { Meaning of "Futuryng connected ecosystem" } \\
\text { Motivations and conditions triggering the adoption } \\
\text { Actors involved in the customers' adoption of I4.0 solutions } \\
\text { The role of Futuryng in the customers' business model } \\
\text { transformation } \\
\text { Personal awareness of the benefits of adopting I4.0 } \\
\text { technologies } \\
\text { Technology by design }\end{array}$ & $\mathrm{CEO}$ \\
\hline $\begin{array}{l}\text { Chief Operating } \\
\text { Officer }\end{array}$ & $\begin{array}{l}\text { Type and nature of the work performed in the company } \\
\text { Personal awareness of the benefits of adopting I4.0 } \\
\text { technologies } \\
\text { Actors involved in the customers' adoption of I4.0 solutions } \\
\text { The sequence of actions performed during the adoption } \\
\text { Value generation } \\
\text { Cost management } \\
\text { Human resource management }\end{array}$ & $\mathrm{COO}$ \\
\hline $\begin{array}{l}\text { Chief IoT Solution } \\
\text { Officer }\end{array}$ & $\begin{array}{l}\text { Type and nature of the work performed in the company } \\
\text { Personal awareness of the benefits of adopting I } 4.0 \\
\text { technologies } \\
\text { Futuryng adoption of standard methodologies for project } \\
\text { implementation } \\
\text { Interoperability between and within systems } \\
\text { Type of implementation phase of an IoT solution release } \\
\text { project }\end{array}$ & CISO \\
\hline
\end{tabular}


coding procedure (Weston et al., 2001). According to Corbin and Strauss (2015) and Locke (2011), we collected all data sources (primary and secondary sources) in a research database, which we coded following the guidelines for the validity and reliability of the qualitative inquiry (Tables 3 and 4): in particular, primary sources are coded considering the manager interviewed; secondary sources are coded accordingly to the platform where the sources were gathered. Therefore, interviews and videos were transcribed, and online data and corporate documents were compiled in a document for analysis. The pieces of evidence were categorized considering the topic dimensions that emerged from the two frameworks under study (Kamble et al., 2018; Brenner, 2018). As listed in Table 4, we use secondary data in the form of the official website of the company, newspaper articles providing information about the activity and acquisitions and technologies used by the firm, and we analyse internal company presentations to clients provided by the interviewees. Additionally, we gathered data through searching Futuryng on google.com, youtube.com, the LinkedIn Futuryng page, Twitter by searching the Hashtag "\#futuryng" and the Facebook Futuryng page. Therefore, the case study triangulates different data sources.

\section{Results}

\subsection{Case description}

Futuryng, with offices in Silicon Valley, New York and Italy, is a Connected Technologies Ecosystem also operating in the field of the IIoT-I4.0 and Blockchain Solutions. The company acts as a supplier of interoperable and pre-connected technologies, which are also called capability. Futuryng refers to its own technologies as capability: one or more features of the technology able to satisfy certain specific functional and operational requirements. The capabilities developed by the Futuryng Ecosystem are shown in Figure 3.

The Futuryng Ecosystem, through its capabilities, is able to design, develop, release, manage and evolve "end-to-end" Solutions (IT-IoT-OT) with rapidity, limited risks and certainty of release. Therefore, Futuryng is a unified, intelligent and collaborative ecosystem designed and enriched on the basis of a wide and modular perimeter of key capabilities for adoption during the implementation of an IIoT project, which triggers the interoperability of the entire ecosystem.

Part of the vision of this firm is to transform a company into an "intelligent digital organism" with the innate ability to "sense and respond". Moreover, Futuryng is focussed

\begin{tabular}{|c|c|c|c|}
\hline Type of source & Provided by & Title & $\begin{array}{l}\text { Secondary } \\
\text { source code }\end{array}$ \\
\hline VIDEO & Youtube (1) & $\begin{array}{l}\text { "InnovAction Digital: Action Institute } \\
\text { intervista Franco Petrucci" }\end{array}$ & SS1.1 \\
\hline VIDEO & Youtube (1) & $\begin{array}{l}\text { "How to Lower Complexity, Risks and } \\
\text { Time To Market of Industrial IoT } \\
\text { Projects" }\end{array}$ & $\mathrm{SS} 1.2$ \\
\hline VIDEO & Youtube (1) & $\begin{array}{l}\text { "La carica dei talenti italiani: start-up verso } \\
\text { la Silicon Valley" }\end{array}$ & SS1.3 \\
\hline VIDEO & LinkedIn (2) & "Futuryng the IoT solutions factory" & SS2 \\
\hline VIDEO & $\begin{array}{l}\text { Futuryng Web Site } \\
\text { (3) }\end{array}$ & "Futuryng the IoT connected ecosystem" & SS3 \\
\hline Internet ARTICLE & Google.it (4) & $\begin{array}{l}\text { "Declara Acquired by Futuryng to } \\
\text { Accelerate Growth" }\end{array}$ & SS4.1 \\
\hline Internet ARTICLE & Google.it (4) & $\begin{array}{l}\text { "Ecco l'Archimede italiano che rende } \\
\text { smart le aziende" }\end{array}$ & SS4.2 \\
\hline PPT & Futuryng Top & "Futuryng Industry $4.0 "$ & SS5 \\
\hline PRESENTATION & Management (5) & & \\
\hline
\end{tabular}

Creating a sustainable I4.0 environment

1767

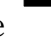


Figure 3.

Capabilities available in solutions developed by the Futuryng ecosystem from SS5

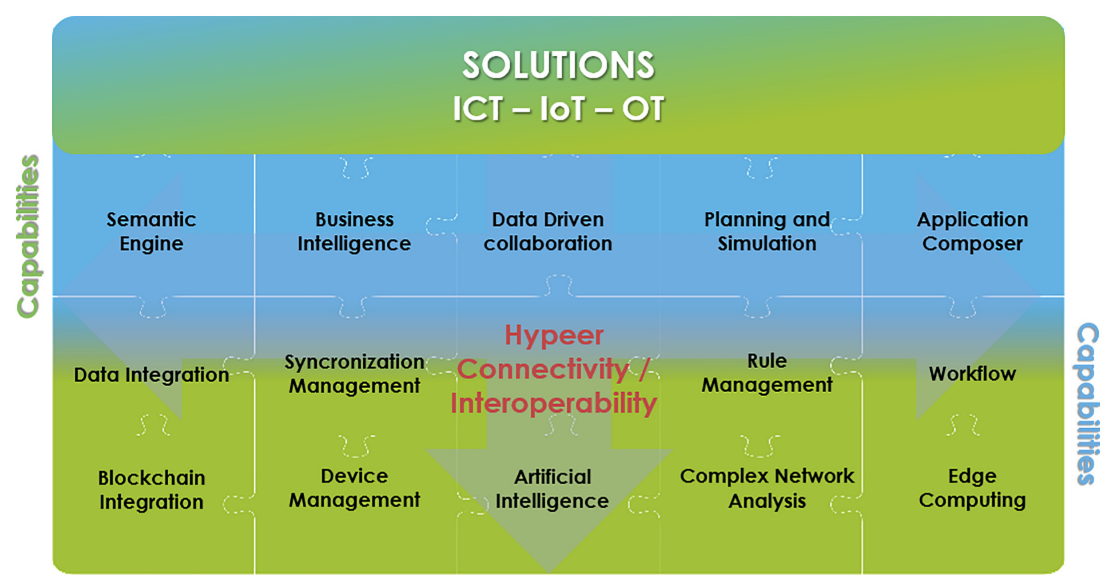

on Blockchain for the organization processes that require an additional layer of distributed information and security. Also, it addresses its activities as a capability provider to system integrators, and the ecosystem technologies are quickly integrated and connected with other technologies in wider solutions. The Futuryng platform allows clients to implement IoT and Blockchain Solutions and to automate the main processes to find the most important features in modularity of pre-connected technologies. In particular, through a hyper connectivity technology/capability, such as Metafyre, which was developed with a "By design approach", Futuryng solves the problem of the interoperability between Microservices, APIs Ecosystems, Legacy Systems, Aggregators and Machines to build the interoperable "Future Systems" that are able to create a connection between operations and the business process of clients with their partners, suppliers and respective customers.

The analysed company conceives, designs and proposes IoT solutions that increase the competitiveness of its clients. Futuryng's main clients are international corporations belonging to different industrial sectors from manufacturing to pharmaceutical. It assists companies' needs in obtaining results through value and innovation and reduces costs, complexity, risks and release times of IoT solutions.

\subsection{The main findings from the sources analysed}

Table 5 shows the most relevant excerpts from interviews and other secondary sources that constitute our pieces of evidence. We divide the evidence related to the case study analysis into six dimensions that are the main topics discussed in the frameworks of the Sustainable I4.0 Ecosystem (Kamble et al., 2018) and Sustainable Transformative Business Models (Brenner, 2018) described in the literature review section.

From the interviews and secondary sources, we can assert that projects of IoT implementation create serious difficulty for companies due to the significant investments required in technology selection, cost analysis, design, integration and release. Investments in IoT Solutions include strong complexity, high risks and long release times, and thus, there is an uncertain Return on Investments. These solutions are able to vertically connect the different technologies needed to deliver the solution and horizontally, the different solutions that underlie processes that need to be connected. Therefore, capabilities are characterized by the result of a complex, fragmented and risky "Ecosystem Game". Due to the type of needs that correspond to the corporate objectives, Futuryng invests in talents who are able to 


\section{Dimensions
I4.0 technologies}

Process integration

COO - SS5

Sustainable outcomes (Economic - Environmental Social) SS1.3 - SS5
Pieces of evidence

CEO - CISO -SS1.1 - The main features of Futuryng technology solutions

(1) Interoperability between and within systems

(2) modularity of pre-connected technologies

(3) Inter-connected ecosystem

(4) Inter-efficient ecosystem; and

(5) Connection between operations and business processes of the company and its partners, suppliers and customers.

The process that leads from the IoT capabilities to IoT solutions is twofold. On the one hand, it is functional, which explains the final objective of the solution and the related use cases. On the other hand, it is technical, which aims at integrating the various technologies within a user's usability (front end) and a functional design of the same solution and its interoperability with the other systems of the company (back end)

We offer capability and solutions (IT-IoT-OT) In the first approach with the customer, we elaborate an assessment based on the functional need and measurement of economic sustainability The I4.0 strategy, planning process and implementation involve many actors such as the company, its consulting firms and its I4.0 technology providers

CEO - COO - CISO - Typically, Futuryng does not come across clients SS2- SS3- SS5 who ask for environmental or social sustainability
Creating a sustainable I4.0

environment

1769 assessments I believe (COO) that the main interest of our customers in the short term is economic sustainability, in terms of greater efficiency and lower production costs, but in the long term, business sustainability will be a topic of increasing relevance Big corporations very often use consulting firms to guide them to business model transformation and also towards sustainability

Futuryng meets three basic needs of customer companies

(1) Solve the problem of interoperability between and within systems

(2) Integrate new technologies/capabilities related to new needs in solutions; and

(3) Create value through continuous innovation

The implementation of I4.0 technologies cannot automatically entail any sustainable effects or those effects cannot be considered or communicated. To obtain sustainable effects, a company must consider sustainable issues in its I4.0 strategy and communication

Table 5.

Pieces of evidence from triangulation of primary and secondary
sources 


\section{Dimensions}

Internal layer

1770
Organizational layer

External environmental layer
CEO - CISO - SS1.1 SS1.2 - SS1.3 - SS5
COO - SS2

CEO - SS1.1 -SS1.2 SS4.1 - SS4.2 - SS5

\section{Pieces of evidence}

Futuryng is a Connected Technologies Ecosystem, which also operates in the field of the Industrial Internet of Things (IoT-Industry 4.0) and Blockchain Solutions

Our company allows customers to reduce operating time or expand their offering by adding other services to their product and they can gather big data to improve the decision-making process

"Capabilities" indicates one or more characteristics of a technology that are combined to satisfy a specific operational-functional need

The implementation of Futuryng ecosystem solutions takes place by considering the three dimensions of the organization: Processes, Roles and Technological Support

The company uses traditional methods of project management (WBS and/or Agile) during the solution implementation relationship with a client, but we are trying to use an approach based on open innovation, which is currently only a marketing tool. However, in theory, this tool can be useful for identifying opportunities from I4.0

Futuryng invests in talents that design and deliver solutions (which deliver key real-time information for automated implementation, key role collaboration and decision-making) and is equally capable of designing, developing, accelerating and globally expanding new market need-driven technologies Futuryng is a technology provider and could come into play when the company decides to plan a business model transformation. Furthermore, with the support of a consulting company, Futuryng can provide the necessary technological tools. From this perspective, it is clear that Futuryng can be the enabling driver for the implementation of a smart business model that also transforms it towards a sustainability perspective

Futuryng's main customers are large international corporations from a wide range of industries. Moreover, Futuryng depends on System Integrators as a pure supplier of technology, which will be integrated and connected with other technologies in wider solutions

The implementation of Technological Solutions derived from the Futuryng Ecosystem capabilities combination takes place following the need for transformation and process innovation, which becomes more crucial through the growing competitiveness of the markets. In addition, by introducing hyper-innovative tools of technological support, there is a consequent impact on both skills and corporate culture

Table 5. 
design and release IoT Solutions and are equally capable in designing, developing, accelerating and globally expanding new technologies driven by market needs.

Futuryng quickly provides complete capability and IoT Solutions with limited integration and development risks and with a determinable value, which responds to three fundamental needs of companies:

(1) solve the problem of interoperability between and within Systems through a new software development paradigm;

(2) integrate new technologies/capability related to new needs in Solutions; and

(3) create value through continuous innovation.

The implementation of technological solutions derived from the Futuryng ecosystem is considered relevant for big companies aware of the need for process transformation and innovation, due to the increasing competitiveness of markets.

Therefore, as mentioned by managers during interviews, "Futuryng could come into play by providing the necessary technological tools when the company decides to BM transformation usually with the support of a business consulting company”. From this perspective, it is clear that Futuryng can be the enabling driver for the implementation of a smart BM and also transform it towards sustainability.

Another important result of the case study analysis is that Futuryng managers already understand that the success of an I4.0 project implementation involve many actors such as the company, its consulting firms and its I4.0 technology providers. They argue that for value creation and success of an I4.0 project, collaboration with all of the actors involved in the business environment is essential.

They also implemented Open Innovation (OI) events and consider OI as "a distributed innovation process based on purposively managed knowledge flows across organizational boundaries, using pecuniary and non-pecuniary mechanisms in line with the organization's business model" (Chesbrough and Bogers, 2014, p. 27). OI requires the collaboration of different actors that are able to face relevant problems; in fact, in the business reality, several firms, such as Futuryng, understand the importance of OI processes as a basis for value co-creation (Ramaswamy and Ozcan, 2014). For Futuryng top managers, the OI process involves disseminating system knowledge, new upcoming technologies, thinking and suggesting ideas and the use case and feasibility of use cases. The OI approach is also capable of releasing Solutions over a short period with a controlled risk level and under a predetermined value. Currently, OI practices are mainly used by Futuryng as communication tools; however, managers consider this approach increasingly relevant for future activities.

\section{Discussion and framework proposition}

\subsection{Discussion of results}

Based on the literature on this topic (Stock and Seliger, 2016, p. 540; Kamble et al., 2018, p. 416), at the macro level, the relationship between sustainability and I4.0 is explained by new BMs, the so-called SSBMs, which are based on a growing intangible component of products and the possibility of developing a value co-creation network regarding a closed-loop product life cycle. At the micro level, the relationship between sustainability and I4.0 is based on the possibility of easily upgrading existing manufacturing devices to achieve sustainable outputs that could be:

(1) Ensuring cost-efficiency and environmental sustainability;

(2) Providing a more suitable work environment, safety at work, increasing knowledge and decision-making ability through a large availability of data;
Creating a sustainable I4.0 environment 
$\mathrm{MD}$

58,8

1772

(3) Improving the efficient allocation of resources and also a sustainable design of processes along the value creation network to ensure an efficient allocation, use and reuse of resources;

(4) And finally, collecting data during the product life cycle to ensure its reuse or remanufacturing or regarding smart products that include some additional services that are able to better satisfy clients.

Through analysis of the results of our case study, we can confirm the literature asserting that with rising global sustainability pressures (Wu et al., 2018; Bocken et al., 2014), collaboration between firms and other key stakeholders is more important (Lowitt, 2013). Mainly, value is no longer created by firms acting autonomously but by firms acting together with external parties through informal arrangements or formal alliances (Beattie and Smith, 2013). Moreover, the case study confirms the impact of I4.0 projects on cost efficiency and environmental sustainability, providing a more suitable work environment, and an increasing availability of data that improves decision-making ability.

Instead, the majority of studies on smart technologies, I4.0 and sustainability are focussed on the perspective of companies that have to implement I4.0 projects and pay little attention to the potential contribution of other key actors or consider the external layer as a background in which company can catch opportunities for new value propositions. Therefore, the shortcoming is that an integrated approach focussed on actors has not been thoroughly analysed; in other words, there is a lack of an integrated framework to interpret how a company can achieve a BM transformation that involves all actors in the environment for the implementation of I4.0 projects considering the sustainability issue.

From our case study, we observed that a company's willingness to adopt I4.0 solutions does not automatically entail any sustainable effects. This is because the I4.0 planning process and implementation involves many actors, and in the least, the company itself, its consulting firms and its I4.0 capability providers. Indeed, to determine sustainable effects from the execution of I4.0 projects, it is necessary to create a Sustainable I4.0 Environment based on the interaction of the aforementioned actors. The initial costs and complexity for the selection of technologies, the uncertain times in the success of their integration, and in the following release of the IoT solutions, place big corporations in a serious and uncertain condition. From this perspective, capability providers, such as Futuryng, act as enablers of successful transition towards a sustainable I4.0 SSBM.

According to Kamble et al. (2018) and Brenner (2018) frameworks, the analysis of the transition towards a SSBM requires a comprehensive approach that involves all six dimensions identified in the two models. Moreover, the case results suggest an enlargement of the meaning of some of the analysed framework's dimensions to include the perspective of capability providers.

\subsection{Framework proposition}

Through the analysis of our case study, we are able to highlight the limitations of the frameworks elaborated by the literature. This indicates the need to develop a Sustainable I4.0 Environment framework and provide a comprehensive vision of the actors involved in that context.

We elaborate this by adding our results to the frameworks provided by the literature regarding the implication of I4.0 on sustainability. We start from the Kamble et al. (2018) framework integrated with Brenner (2018) to better understand the contribution of capability providers into a Sustainable I4.0 Environment. As shown in Figure 4, we mix Brenner's individual and organizational layers with Kamble's process integration. Additionally, we specify the external layer as the actors involved, such as capability providers and consulting 


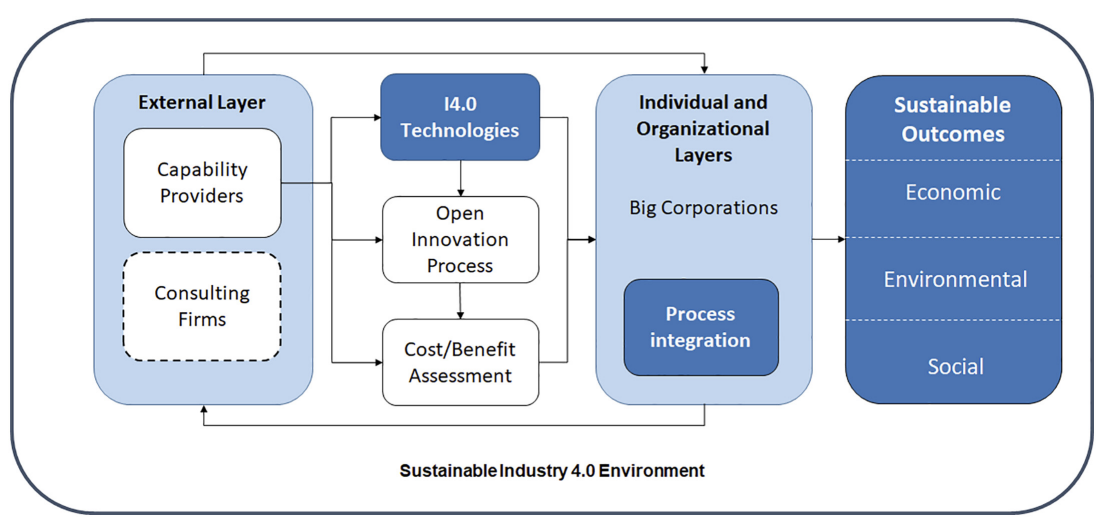

Creating a sustainable I4.0 environment

1773

Figure 4.

Sustainable industry 4.0 environment

firms that help big corporations implement I4.0 projects and act together with external parties to the firm through informal arrangements or formal alliances instead of considering the external layer as only a social, economic and technological background.

Moreover, we reinterpret the technological background of Brenner's model as a component of the external layer related to the capability providers and as an input of the organizational layer, which is named the I4.0 Technologies dimension of Kamble's framework. Other inputs that emerge from the case study as potential contributions of capability providers to the Sustainable I4.0 Environment are the proposed OI processes and the capability to assess the technological costs and benefits during a BM transformation. From this perspective, technology suppliers of the external layer are able to provide capabilities - and not just technologies - to the organizations and their employees, with a greater guarantee of success if they activate an OI process and provide an accurate assessment of the cost/benefits of implementation of I4.0 projects that bring to the transformation of BMs.

After the integration into BMs and processes of I4.0 solutions, big corporations first achieve economic sustainability in terms of resource consumption, efficiency and cost savings in process development. Then, they achieve social sustainability in terms of increased knowledge and better working conditions of both employees and managers. This virtuous process is also able to produce benefits in terms of environmental sustainability of companies' activities. Therefore, we can argue that the achievement of sustainable outcomes of big corporation SSBM transformation requires a Sustainable I4.0 Environment approach.

\section{Conclusions}

The aim of this research was to explore the potential contribution of capability provider in the Sustainable I4.0 Environment as a driver for the management decision of SSBM transformation of big corporations. We start from the assumption that the implementation of smart technologies involves a request for collaboration (Agostini and Nosella, 2019) because, in many cases, big companies cannot internally develop all the technologies needed to implement IIoT solutions and make them interoperable with already adopted and existing technologies (which is related to both economic concerns and points out the great risk associated with the success of the results).

We also reviewed the literature supporting the relationship between I4.0 and sustainability (Kamble et al., 2018; Braccini and Margherita, 2019; Gazzola et al., 2019) and consider I4.0 as a paradigm that will help companies move towards sustainable value creation (Stock and Seliger, 2016, p. 541). 
However, the literature so far is mainly theoretical and focussed on the development of sustainable I4.0 only in implementing firms and in specific countries (i.e. Germany, the United States and China). Unlike other studies, we investigate the transition towards SSBM through the analysis of a different key actor of the I4.0 environment, that is, the capability provider. In fact, due to the complexity of several technologies needed to create the I4.0 CPS, big corporations are not able to internally develop all the technologies and then integrate these technologies into business processes without the support of other market players (Lombardi, 2019; Adams et al., 2012). The complexity is managed by capability providers and considers the most efficient way to combine both different devices, to collect relevant information from the physical system to the virtual one, and employees' values, knowledge and expertise to identify the most efficient and effective design of integration between humans and machines. In this view, we use a case study methodology and select Kamble et al. (2018) and Brenner (2018) frameworks to analyse SSBM transformation in an I4.0 Environment.

The case study analysis allows us to investigate the I4.0 Ecosystem and answers the call to adopt a comprehensive and integrated perspective in studying the I4.0 phenomenon from inside and outside companies' boundaries to effectively understand how I4.0 can foster sustainable outcomes (Agostini and Nosella, 2019; McKinsey and Company, 2016). Moreover, the Futuryng case study helps us to develop a framework, called the Sustainable I4.0 Environment, in which we identify key actors as external layer, the contribution of capability providers to $\mathrm{BM}$ transformation, the internal and organizational layer and sustainable outcomes.

Our comprehensive and integrated framework can guide the decision process of the transition from a TBM to a Sustainable I4.0 BM. In the context of our analysis, big corporations consider the BM design the source of economic sustainability for the corporation in terms of: increasing revenues, generating profit for the entrepreneur and investors and becoming more competitive because of growing market globalization. Typically, in the design of a BM, big global corporations ask for consulting firms specialized in supporting and managing SSBM choices. In this process, Futuryng capabilities are requested for the operational phase, and smart technological solutions are implemented to support business processes and accelerate the achievement of strategic objectives.

Finally, moving from the analysis of the main findings of the case study and from a recent systematic literature review (Piccarozzi et al., 2018, p. 19), we argue that the topic of OI is of great interest. However, the general application of OI and innovation processes are still deployed at an unstructured level and too often addressed and discussed in conferences and communication events and less in the company's daily life.

\subsection{Implications and limitations of the study}

This framework has an impact for both academics and practitioners. Academics are impacted because it overcomes the vision of implementation of the I4.0 as a process that affects individual companies and therefore, exposes the need for an in-depth study of the environment, which should not only be considered as an external background or an internal context but also as a layer in which a multiplicity of actors operates to foster sustainable outcomes. Practitioners are impacted because the proposed framework leads towards internal and external integration with other companies through the awareness of the need of a Sustainable Industrial Value Creation Environment (Kiel et al., 2017) as an open and comprehensive process involving all stakeholders.

The article suffers from several limitations that are worth consideration for future research activities. Therefore, future research needs to expand the study of OI and innovation processes, such as instruments of certainty, standardization and value creation, in the implementation of sustainable I4.0 and technology-based projects. Moreover, using interviews, we identify the main contributions of capability providers in terms of I4.0 
solutions, OI and benefit and cost assessment, but we do not analyse their relevance in quantitative terms; otherwise, it could be an interesting perspective for the future. Also the investigation of the cause-effect relationship among contributions of each actor could be interesting, as well as the investigation of the Sustainable I4.0 Environment from the perspective of consulting firms.
Creating a sustainable I4.0 environment

\section{References}

Adams, R., Bessant, J., Jeanrenaud, S., Overy, P. and Denyer, D. (2012), "Innovating for sustainability: a systematic review of the body of knowledge", Network for Business Sustainability Report, pp. 1-107.

Agostini, L. and Nosella, A. (2019), "The adoption of Industry 4.0 technologies in SMEs: results of an international study”, Management Decision, Vol. 58 No. 4, pp. 625-643.

Baheti, R. and Gill, H. (2011), "Cyber-physical systems”, The Impact of Control Technology, Vol. 12 No. 1, pp. 161-166.

Beattie, V. and Smith, S.J. (2013), "Value creation and business models: refocusing the intellectual capital debate", The British Accounting Review, Vol. 45 No. 4, pp. 243-254.

Beier, G., Niehoff, S., Ziems, T. and Xue, B. (2017), "Sustainability aspects of a digitalized industry-a comparative study from China and Germany", International Journal of Precision Engineering and Manufacturing-Green Technology, Vol. 4 No. 2, pp. 227-234.

Birkel, H.S., Veile, J.W., Mueller, J.M., Hartmann, E. and Voigt, K. (2019), "Development of a risk framework for industry 4.0 in the context of sustainability for established manufacturers", Sustainability, Vol. 11 No. 2, pp. 384-411.

Bocken, N.M.P., Short, S.W., Rana, P. and Evans, S. (2014), "A literature and practice review to develop sustainable business model archetypes”, Journal of Cleaner Production, Vol. 65, pp. 42-56.

Bonilla, S., Silva, H., Terra da Silva, M., Franco Gonçalves, R. and Sacomano, J. (2018), "Industry 4.0 and sustainability implications: a scenario-based analysis of the impacts and challenges", Sustainability, Vol. 10 No. 10, pp. 3740-3764.

Braccini, A.M. and Margherita, E.G. (2019), "Exploring organizational sustainability of industry 4.0 under the triple bottom line: the case of a manufacturing company", Sustainability, Vol. 11 No. 1, pp. 36-53.

Brenner, B. (2018), "Transformative sustainable business models in the light of the digital imperative - a global business economics perspective", Sustainability, Vol. 10 No. 12, pp. 4428-4453.

Bressanelli, G., Adrodegari, F., Perona, M. and Saccani, N. (2018), "Exploring how usage-focused business models enable circular economy through digital technologies", Sustainability, Vol. 10 No. 3, pp. 639-660.

Cezarino, L.O., Liboni, L.B., Oliveira Stefanelli, N., Oliveira, B.G. and Stocco, L.C. (2019), "Diving into emerging economies bottleneck: industry 4.0 and implications for circular economy", Management Decision. doi: 10.1108/MD-10-2018-1084.

Chesbrough, H. and Bogers, M. (2014), "Explicating open innovation. Clarifying an emerging paradigm for understanding innovation", in Chesbrough, H., Vanhaverbeke, W. and West, J. (Eds), New Frontiers in Open Innovation, Oxford University Press, Oxford, pp. 3-28.

Corbin, J. and Strauss, A. (2015), Basics of Qualitative Research. Techniques and Procedures for Developing Grounded Theory, SAGE Publications, Thousand Oaks, CA.

De Man, J.C. and Strandhagen, J.O. (2017), "An Industry 4.0 research agenda for sustainable business models", Procedia Cirp, Vol. 63, pp. 721-726.

De Sousa Jabboura, A.B.L., Chiappetta Jabboura, C.J., Foropona, C. and Filhob, M.G. (2018), "When titans meet - can industry 4.0 revolutionise the environmentally-sustainable manufacturing wave? The role of critical success factors", Technological Forecasting and Social Change, Vol. 132, pp. 18-25. 

Publishers, Stoney Creek, CT.

Etzkowitz, H. and Zhou, C. (2006), "Triple Helix twins: innovation and sustainability", Science and Public Policy, Vol. 33 No. 1, pp. 77-83.

Gazzola, P., Del Campo, A.G. and Onyango, V. (2019), "Going green vs going smart for sustainable development: quo vadis?”, Journal of Cleaner Production, Vol. 214, pp. 881-891.

Kamble, S.S., Gunasekaran, A. and Gawankar, S.A. (2018), "Sustainable Industry 4.0 framework: a systematic literature review identifying the current trends and future perspectives", Process Safety and Environmental Protection, Vol. 117, pp. 408-425.

Kiel, D., Müller, J.M., Arnold, C. and Voigt, K.I. (2017), "Sustainable industrial value creation: benefits and challenges of industry 4.0", International Journal of Innovation Management, Vol. 21 No. 8, pp. 1-21.

Lamboglia, R., Mancini, D. and Piedepalumbo, P. (2017), "New business model for value co-creation in smarter universities", in Marchi, L. and Lombardi, R. (Eds), Il Governo Aziendale tra Tradizione e Innovazione, Franco Angeli, pp. 68-83.

Lin, K., Shyu, J. and Ding, K. (2017), “A cross-strait comparison of innovation policy under industry 4.0 and sustainability development transition”, Sustainability, Vol. 9 No. 5, p. 786.

Locke, K.D. (2011), Grounded Theory in Management Research, SAGE Publications, London.

Lombardi, R. (2019), "Knowledge transfer and organizational performance and business process: past, present and future researches”, Business Process Management Journal, Vol. 25 No. 1, pp. 1-9,.

Lowitt, E. (2013), The Collaborative Economy, Jossey-Bass (Wiley), San Francisco.

Luthra, S., Kumar, A., Zavadskas, E.K., Manglad, S.K. and Garza-Reyes, J.A. (2019), "Industry 4.0 as an enabler of sustainability diffusion in supply chain: an analysis of influential strength of drivers in an emerging economy", International Journal of Production Research, pp. 1-17.

Martínez-Olvera, C. and Mora-Vargas, J. (2019), "A comprehensive framework for the analysis of industry 4.0 value domains", Sustainability, Vol. 11 No. 10, p. 2960.

McKinsey and Company (2016), Industry 4.0 after the Initial Hype, McKinsey Digital, available at: https://www.mckinsey.de/files/mckinsey_industry_40_2016.pdf.

Müller, J.M. and Voigt, K.I. (2018), "Sustainable industrial value creation in SMEs: a comparison between industry 4.0 and made in China 2025", International Journal of Precision Engineering and Manufacturing-Green Technology, Vol. 5 No. 5, pp. 659-670.

Nascimento, D.L.M., Alencastro, V., Quelhas, O.L.G., Caiado, R.G.G., Garza-Reyes, J.A., Rocha-Lona, L. and Tortorella, G. (2019), "Exploring Industry 4.0 technologies to enable circular economy practices in a manufacturing context”, Journal of Manufacturing Technology Management, Vol. 30 No. 3, pp. 607-627.

Piccarozzi, M., Aquilani, B. and Gatti, C. (2018), "Industry 4.0 in management studies: a systematic literature review", Sustainability, Vol. 10 No. 10, p. 3821.

Rajkumar, R., Lee, I., Sha, L. and Stankovic, J. (2010), "Cyber-physical systems: the next computing revolution”, Design Automation Conference, IEEE, Anaheim, CA, pp. 731-736.

Rajput, S. and Singh, S.P. (2019a), "Connecting circular economy and industry 4.0", International Journal of Information Management, Vol. 49, pp. 98-113.

Rajput, S. and Singh, S.P. (2019b), "Identifying Industry 4.0 IoT enablers by integrated PCA-ISMDEMATEL approach", Management Decision, Vol. 57 No. 8, pp. 1784-1817.

Ramaswamy, V. and Ozcan, K. (2014), The Co-creation Paradigm, Stanford University Press, Standford, CA.

Schiavone, F., Paolone, F. and Mancini, D. (2019), "Business model innovation for urban smartization", Technological Forecasting and Social Change, Vol. 142, pp. 210-219. 
Stock, T. and Seliger, G. (2016), “Opportunities of sustainable manufacturing in industry 4.0”, Procedia Cirp, Vol. 40, pp. 536-541.

Stock, T., Obenaus, M., Kunz, S. and Kohla, H. (2018), "Industry 4.0 as enabler for a sustainable development: a qualitative assessment of its ecological and social potential”, Process Safety and Environmental Protection, Vol. 118, pp. 254-267.

Trequattrini, R., Shams, S., Lardo, A. and Lombardi, R. (2016), "Risk of an epidemic impact when adopting the Internet of Things: the role of sector-based resistance", Business Process Management Journal, Vol. 22 No. 2, pp. 403-419.

WCED-World Commission on Environment and Development, B. C. (1987), "Our Common Future. Report of the world commission on environment and development", available at: https:/sswm.info/sites/ default/files/reference_attachments/UN\%20WCED \%201987\%20Brundtland\%20Report.pdf.

Weston, C., Gandell, T., Beauchamp, J., McAlpine, L., Wiseman, C. and Beauchamp, C. (2001) “Analyzing interview data: the development and evolution of a coding system”, Qualitative Sociology, Vol. 24 No. 3, pp. 381-400.

Wu, J., Guo, S., Huang, H., Liu, W. and Xiang, Y. (2018), "Information and communications technologies for sustainable development goals: state-of-the-art, needs and perspectives", IEEE Communications, Surveys \& Tutorials, Vol. 20 No. 3, pp. 2389-2406.

Yin, R.K. (2014), Case Study Research: Design and Methods, SAGE, Los Angeles.

\section{Further reading}

Benbasat, I., Goldstein, D.K. and Mead, M. (1987), "The case research strategy in studies of information systems", MIS Quarterly, Vol. 11 No. 3, pp. 369-386.

Berg, B.L. (2007), Qualitative Research Methods for the Social Sciences, Pearson Education, Long Beach, CA.

Creswell, J.W., Hanson, W.E., Clark Plano, V.L. and Morales, A. (2007), "Qualitative research designs: selection and implementation”, The Counseling Psychologist, Vol. 35 No. 2, pp. 236-264.

Dubé, L. and Paré, G. (2003), "Rigor in information systems positivist case research: current practices, trends, and recommendations", MIS Quarterly, Vol. 27 No. 4, pp. 597-636.

Lüdeke-Freund, F. (2010), Towards a Conceptual Framework of Business Models for Sustainability, ERSCP-EMU Conference in Delft, Netherlands, pp. 1-28.

Stokes, D. and Bergin, R. (2006), "Methodology or 'methodolatry'? An evaluation of focus groups and depth interviews", Qualitative Market Research: An International Journal, Vol. 9 No. 1, pp. 26-37.

\section{Corresponding author}

Alessandra Lardo can be contacted at: alessandra.lardo@uniparthenope.it

For instructions on how to order reprints of this article, please visit our website:

www.emeraldgrouppublishing.com/licensing/reprints.htm

Or contact us for further details: permissions@emeraldinsight.com 